\title{
Editorial
}

\section{Neomercado y neodemocracia}

Aunque parezca extrano enfrentamos unas contradicciones similares a las de los paises del Este europeo en su fase de transición hacia el mercado y la democracia. No es que nosotros estemos rompiendo el cascarón de una economia centralmente planificada y políticamente controlada por un partido único, pues nuestros partidos han sido variados y se eclipsan o subdividen cuando dejan el poder. Más bien acarreamos una economia desvencijada por la guerra, la adversa coyuntura internacional, el divisionismo social interno social y económico, más una cierta dosis de corrupción generalizada. A la salida del tunel de la crisis nos encontramos con nuevos vientos que soplan en dirección contraria: el neoliberalismo económico y la neodemocracia sociopolítica. Al parecer, los paises europeos occidentales han ido logrando un matrimonio equilibrado de estos dos componentes de la convivencia social. "Conservadores en lo económico, socialdemócratas en todo lo demás" decia la macroencuesta de enero 1990.

Pero, para nosotros la transición hacia el neomercado y la neodemocracia encierra todas las contradicciones sociales latentes en el eslogan de "cambiar para mejorar". Como en nuestra historia ha habido más bien mercado sin democracia, o mercado antidemocrático, es difícil aceptar de repente que nuestro mercado ha cambiado su tonalidad social o que le han injertado unas entranas de solidaridad. Más bien, el presentimiento es todo lo contrario; que pasemos de una agresividad y competitividad bélica a una competividad y agresividad empresarial. Incluso hay una gran dif́erencia en esta transición de poderes; en la competencia bélica ninguno de los dos bandos ha sido vencedor ni vencido, pero es difícil prever que suceda lo mismo con la competitividad del 
mercado, donde el término privatización ha significado históricamente concentración. No es que sea éste el objetivo directo de la privatización, fundamentado en la mayor eficiencia y mejor optimización de los escasos recursos, pero la historia suele tener más fuerzas que las teorlas.

Por otra parte, la competencia bélica es tan brutal por si misma, destruye en un instante tantas vidas inocentes, junto con lo mejor del capital nacional, que en cierto momento secreta los antibióticos de la concertación y reconciliación nacional. Como en nuestra economia de mercado estos mismos efectos se realizan, pero más lentamente, (ahl está también el deterioro ecológico), se permite el libre juego de las fuerzas del mercado, consagradas como leyes de la oferta y de la demanda. En el fondo se legitiman las fuerzas, se las disimula como sociedades anónimas, en nuestro caso antidemocráticas. Incluso se reconoce que en un inicio (sin fecha-calendario) los ajustes estructurales del mercado generan efectos discriminantes a compensar con una solidaridad que venga del Estado, pero no del mercado. Parecería que estamos convenciendo a un paciente, que será intervenido quirúrgicamente, y que después de unos amargos dias en cuidados intensivos saldrá totalmente rejuvenecido. No es de extranar que haya reacciones adversas a las leyes de la economía del mercado de parte de quienes más han sufrido históricamente de las fuerzas de la guerra y de las fuerzas del mercado, sin haber sido nunca sujetos de cuidados intensivos. (Editorial: REALIDAD, Nos. 19-20)

Los fríos análisis y ponderaciones macroeconómicas del producto nacional, reservas internacionales, deficits decrecientes, inflación frenada... (orquestas por FUSADES) tienen la misma resonancia que los partes metereológicos para quienes se debaten por el pan nuestro de cada dia sin que puedan endulzarlo con las gotas del rebalse. Que tampoco se moleste el GAES-MIPLAN porque el título de su informe económico-1990, "El Salvador..., un país de propietarios", se interprete ambiguamente, por aquello de "los catorce". Estas interpretaciones son catalizadas por el sesgo unilateral de las reformas económicas, impuestas muchas de ellas sin el menor diálogo.

Se lleva a cabo una reforma bancaria fundamentada en dos objetivos: saneamiento y privatización, haciendo de la privatización la estrategia del saneamiento. Para legitimar la teoria se desacreditó la malversación del sector público, pero al iniciar el saneamiento bancario se descubre que los morosos al por mayor son grandes empresas del sector privado. ¿Quién quebró al sistema bancario? Por lo menos esto pone en duda que saneamiento y privatización sean hermanos gemelos. 
Se aprecian tratamientos diferentes para las instituciones públicas y privadas. Es mucho lo que se ha hablado de la ineficiencia del Estado y por ello se recorta su responsabilidad económica. O bien, el IRA es contablemente deficitario y se le cierra. Pero, ¿qué sucede con las empresas mercantiles, muchas de ellas grandes morosos? - No muestran una suficiente eficiencia para competir en un mercado abierto. No se les aplica la noma del IRA, ni se las puede privatizar porque ya son privadas, ni se las puede nacionalizar porque engordariamos al sector publico. La salida está en la "reconversión industrial", solución totalmente necesaria aunque no muy clara en su concepción, y que en el fondo viene a reconocer los privilegios fiscales de que gozó el sector y el estancamiento empresarial que le siguió. Lo que es estatal o público se reduce o se cierra; lo privado se reconvierte, sin ponderar de antemano si todo el proceso nos reconvierte a situaciones mono u oligopolisticas. No se puede evitar la contradicción más que aparente entre el neomercado y la neodemocracia, latente en la interpretación del cambiar para mejorar.

La contradicción se hace más patente cuando pasamos al tema de "la reconstrucción de postguerra: el desafio económico y social", prestando el titulo que CENITEC invitó a discutir en reciente seminario (2708-91). En este foro se nos presentó "el plan de reconstrucción del Gobierno". Es laudable que se quiere prestar atención a los efectos de la guerra, que se ubiquen zonas-objetivos donde aplicar programas de asistencia económico-social de corte y mediano plazo, desde una ayuda alimentaria inicial hasta pequehas obras de infraestructura fisica sugeridas en cabildos abiertos. Es comprensible que las oficinas ministeriales y el FISS visiten e inviten a instituciones educativas privadas para solicitar su concertación y colaboración a este proceso de reparaciones físicas y humanas de postguerra, a condición de que no se aprovechen de la generosidad ajena para publicidad electoral propia. Pero lo que no es laudable ni comprensibles que no se haga referencia a las causales de la guerra; que todo eso que se quiere reparar en la postguerra es la causa de la preguerra. Se recurre a las entranas de misericordia y a la colaboración de tantas instituciones privadas para montar la reconstrucción de postguerra, se recurre al aporte local de los cabildos abientos para avalar un amplio apoyo democrático, pero no se acepta semejante concertación y cabildeo para reformular los ejes del modelo económico. Se dividen y desarticulan los dos grandes objetivos del desarrollo de postguerra: un crecimiento fuerte y sostenido con amplio empleo, junto con una distribución más equitativa de los frutos del crecimiento. Se pretende una colaboración ampliada sin un sacrificio generalizado. $Y$ asi es dificil la reconstrucción. 
El mismo diálogo ha quedado empantanado por una visión antidemocrática del fenómeno guerra. La guerra es descrita superticialmente como dos bandos armados ideológicamente enfrentados. Ante el fracaso de las ideologias del Este europeo, los insurgentes pienden su razón de ser y la paz vendrá con la simple desmobilización de los alzados en armas. La última reunión de los Presidentes centroamericanos avalaría esta simplista visión. (Proceso, № 482). Otra prueba más de la visión antidemocrática de la guerra, que simplifica la solución al sustituir las armas por las urnas electorales, sin otras reformulaciones del modelo económico, que si nos convirtió en sujetos de crédito del FMI, no acaba de convertirse en sujeto de crédito del fondo nacional.

Hemos recibido una ayuda militar y una ayuda económica. Ayudamilitar son dos términos contradictorios y antidemocráticos. El calificativo de militar se ha convertido en el sustantivo de militarismo, con todas las implicaciones en la deformación del estado de derecho, en la impunidad judicial y en los reclamos de depuráción y desmilitarización. También la ayuda económica es contradictoria y antidemocrática, si por ayuda económica entendemos principalmente la imposición de un modelo que reajusta algunas variables macrooconómicas de la contabilidad nacional, y para ello ajusta más fuertemente otras estructuras sociales y la mayoría de las contabilidades particulares.

Hay una sana preocupación por la reconversión industrial y la reconstrucción de postguerra. Pero esto no agota el problema de la reconversión nacional. Hay que reconvertir artículos de la Constitución; hay que reconvertir las teorias económicas para que los resultados macroeconómicos se fundamenten en mejores estructuras. Hay que reconvertir el plan de desarrollo para fusionar lo social con lo económico, es decir la equidistribución con el crecimiento. Hay que reconvertir el concepto de solidaridad, que lejos de reducirse a transferencias y donaciones sociales, signifique, a todos los niveles, ser solidarios de la pobreza y de los derechos humanos. Hay que reconvertir la teorla de la guerra, de sus efectos y sobre todo de sus causas. Hay que reconvertir la neoeconomia en neodemocracia. $Y$ qüédan por reconvertir los valores cívicos y espirituales... 